\title{
Islanding Detection in Distribution Networks with Distributed Energy Resources before Main Circuit Breaker Opening
}

\author{
M. R. Vatani*, M. J. Sanjari, G. Gharehpetian \\ Electrical Engineering Department, Amirkabir University of Technology, 424, Hafez Avenue, Tehran, Iran \\ *Corresponding Author: m_r_vatani@yahoo.com
}

Copyright (C) 2014 Horizon Research Publishing All rights reserved.

\begin{abstract}
The new method for islanding detection in distribution network is presented in this paper. The islanding conditions should be detected as soon as possible. Therefore, this paper presents a new method that detects the islanding condition before main circuit breaker opening. The proposed method is based on the zero sequence angle of the current measured at the utility side of the utility circuit breaker. The measured parameter has a unique characteristic in the islanding conditions. The discrete wavelet transform is applied to extract the feature from the measured angle. This feature determines the islanding condition from non-islanding ones. The accuracy and efficiency of the proposed method for islanding detection is confirmed by simulation results. This method is effective for islanding detection in distribution network with high penetration of distributed generations. The proposed method causes no power quality problems for distribution network and can be developed in smart grids.
\end{abstract}

Keywords Islanding Detection, Distributed Generation, Discrete Wavelet Transform, Utility Current Zero Sequence

\section{Introduction}

Due to the development of semiconductor technologies and the environmental commitments, more Distributed Energy Resources (DERs) have been used in distribution networks. The Microgrid (MG) is defined as a cluster of Distributed Generations (DGs), loads and energy storage systems [1-3]. Usually, the MG operates in grid connected mode. The MG should disconnect when a fault occurs in the upstream network. This MG operation mode is called islanding operation mode. In grid-connected operation mode, the frequency and the voltage of the MG is maintained within a tight range by the main grid. The frequency of the MG has a strong relation with the active power of the MG in an islanded operation mode. Therefore, the control strategy of the DGs in an islanding operation mode is the frequency and voltage control. The islanding detection methods should detect the islanding condition as soon as possible with minimum non-detection zone (NDZ). NDZ is "the difference between active and reactive power on the island when islanding cannot be detected by the corresponding method" [4]. The islanding detection method can be classified into the remote methods and the local methods.

The local methods monitor the network parameters such as voltage, current, frequency and active power at the terminal of DGs or at the point of common coupling (PCC). The measured parameters have a considerable variation when the islanding condition is occurred. The local methods classified into the active methods and the passive methods. The implementation of the passive methods is simple but their NDZ are large. The active methods have less NDZ than the passive methods but cause the power quality problems in distribution network because of injecting the continual disturbances to it. Voltage unbalance [5], rate of change of output power [6], rate of change of frequency [7], active frequency drift [8] and Slip-Mode Frequency Shift Algorithm [9] are some of the main local methods.

The remote methods monitor the main circuit breaker operation. The main circuit breaker opening causes the islanding condition occurrence. Therefore, these methods detect the islanding conditions by the main circuit breaker opening. The NDZ of the remote methods is minimum but they are expensive methods and their implementation is difficult. Transfer trip scheme [10] and Power line signaling [11] are two example approach of the remote method.

This paper presents a new method for islanding detection in distribution network. This method is based on the zero sequence angle of the current measured at the utility side of the main circuit breaker. Selecting this point as the measuring point causes the fast islanding detection. The measured angle is processed by discrete wavelet transform to extract the characteristics of the measured current, by which the islanding condition can be detected fast and accurately. Three scenarios are investigated to confirm the accuracy of 
the proposed method.

The remainder of this paper is organized as follows: the proposed method is presented in section 2; simulation and its result are expressed in section 3 and conclusions are drawn in section 4 .

\section{Proposed Method}

The islanding conditions occur when the utility circuit breaker is opened. The fault happening in the upstream network is the main reason for the circuit breaker opening. When a fault is occurred, it takes a time to clear the fault current. The relay and the utility circuit breaker need the time for sensing and clearing the fault current. This time can be saved for islanding detection and changing the control strategy by movement the measuring point from the PCC (in the local methods) to the utility side of the utility circuit breaker (in the proposed method). The local methods detect the islanding conditions by change in the monitored values (measured at PCC) caused by utility circuit breaker opening. In this paper, the measuring point is moved to the utility side of circuit breaker. Due to this movement the islanding condition can be detected faster than the local methods. Also, the islanding conditions can be detected before circuit breaker opening by determination the events which cause circuit breaker opening.

The proposed method measures the current zero sequence angle at the utility side of the circuit breaker. This measured parameter is processed by the discrete wavelet transform (DWT). The DWT extract the feature from the measured parameter to distinguish between the islanding conditions from non-islanding ones. The DWT is the time-frequency domain analysis that is used widely in power system analysis [d]. The DWT of a discrete function $x(k)$ can be defined as follows:

$$
D W T(m, k)=\frac{1}{\sqrt{a_{0}^{m}}} \sum_{n} x(n) \Psi\left(\frac{k-n a_{0}^{m}}{a_{0}^{m}}\right)
$$

where, $m$ and $n$ are positive integers employed to define scaling and translating factors applied to the selected mother wavelet $\psi$. It is considerable that by using a lower decomposition level, the response time of the anti-islanding detection algorithm will be shorter. The Coiflets wavelet family is applies in this paper to extract the feature.

Because of using the DWT analysis, the feature can be extracted in transient state of measured parameter. So the required time in islanding detection can be decreased. The time constant of transient state is less than the time constant of DG's control strategy. Therefore, the islanding detection is not affected by DG's control strategy. Because of the new measuring point at utility side of the utility circuit breaker, the sensitivity of measured parameter to the DG's disturbances is low. Therefore, the proposed method is an effective method for islanding detection in distribution network with high penetration of DGs.

\section{Simulation Results}

The proposed method is simulated in three cases. Fig. 1 shows the under test network and the network parameters are found in Table 1. this network is simulated by MATLAB simulink software and the utility current zero sequence angle is processed by MATLAB/Toolbox software for DWT analysis. Three cases are assumed to confirm the accuracy of the proposed method. These cases are: the malfunction of the utility circuit breaker, the utility circuit breaker opening caused by a fault happening in the upstream network and the load reduction. The first and second cases are the islanding condition and should be detected as soon as possible. The third case is the non-islanding condition.

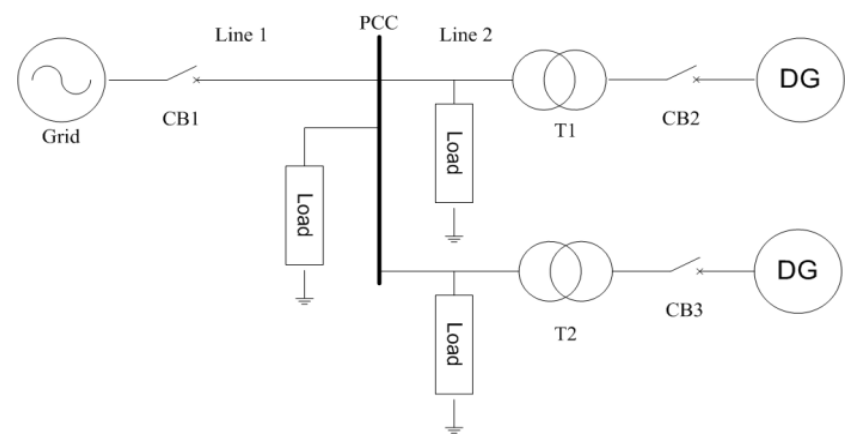

Figure 1. The studied network

Table 1. The studied network parameters

\begin{tabular}{|c|c|c|c|}
\hline Parameter & Value & Line Parameter & Value \\
\hline $\mathrm{V}_{\text {source }}$ & $25 \mathrm{KV}$ & Length 1 & $10 \mathrm{Km}$ \\
\hline $\mathrm{Z}_{\text {source }}$ & $6.45+\mathrm{j} 14.4 \Omega$ & Length 2 & $1 \mathrm{Km}$ \\
\hline $\mathrm{R}_{\text {load }}$ & $347 \Omega$ & $\mathrm{R}_{1}$ & $0.2138 \Omega / \mathrm{km}$ \\
\hline $\mathrm{L}_{\text {load }}$ & $0.368 \mathrm{H}$ & $\mathrm{R}_{0}$ & $0.3875 \Omega / \mathrm{km}$ \\
\hline $\mathrm{C}_{\text {load }}$ & $19.09 \mu \mathrm{F}$ & $\mathrm{X}_{1}$ & $0.3928 \Omega / \mathrm{km}$ \\
\hline DG TX ratio & $25 / 0.48$ & $\mathrm{X}_{0}$ & $1.8801 \Omega / \mathrm{km}$ \\
\hline DG TX X1 & $6 \%$ & $\mathrm{~B}_{1}$ & $\begin{array}{c}4.2315 \\
\mu \mathrm{S} / \mathrm{km}\end{array}$ \\
\hline & & $\mathrm{B}_{0}$ & $\begin{array}{c}1.60585 \\
\mu \mathrm{S} / \mathrm{km}\end{array}$ \\
\hline
\end{tabular}

The Coiflets family wavelet is applied in the proposed method. The simulation shows that the Coif1 in the first decomposition level is the best for extracting the feature. The feature that is selected for islanding detection is the maximum level of the DWT first level. The needed time for DWT processing is minimized by using the first level decomposition.

In the first case, the malfunction of the utility circuit breaker is occurred at the $t=0.08 \mathrm{~s}$. Therefore, this case is an islanding condition. The utility current signal is shown in Fig. 2a and the utility current zero sequence angle is shown in Fig. 2b. The DWT $1^{\text {st }}$ level signal is shown in Fig. 2c. This figure shows that the feature value for this case is equal to 0.95 . The maximum Value for other levels is found in Table 2. This table shows that the DWT $1^{\text {st }}$ level has the minimum value for the selected feature than the other 
levels.
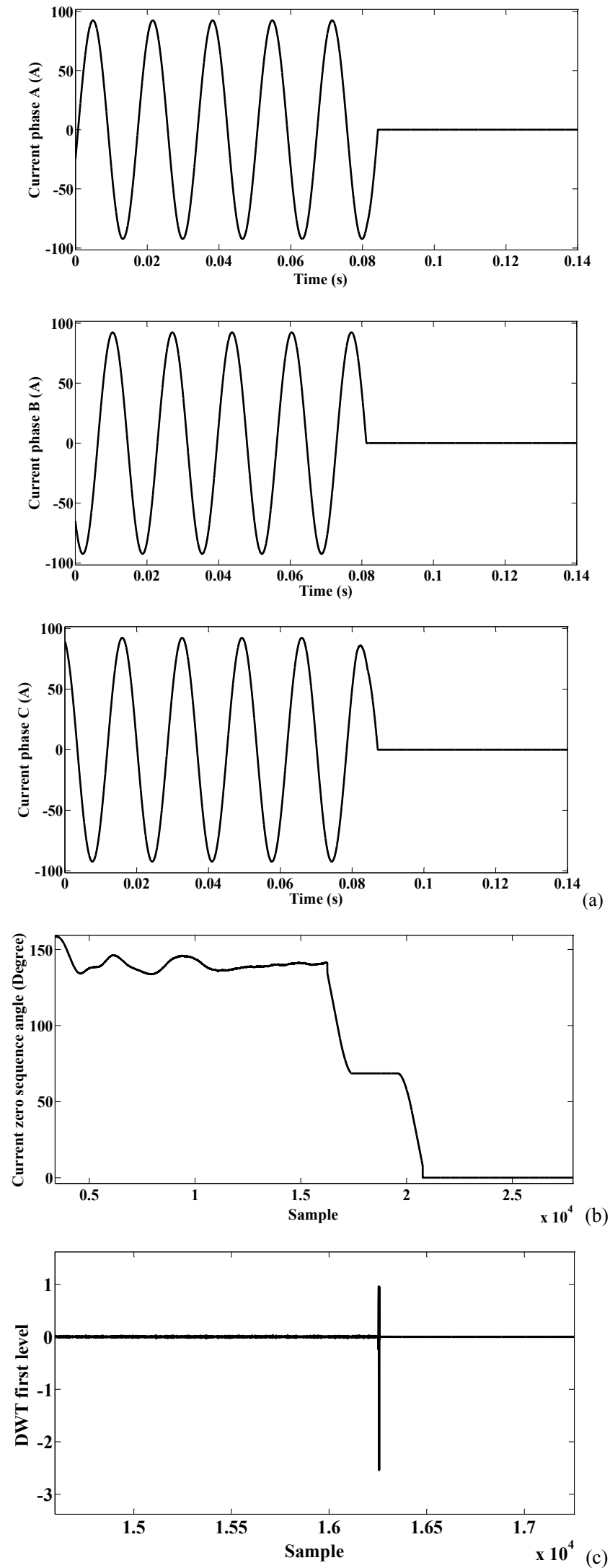

Figure 2. (a) Utility current signal, (b) zero sequence angle of utility current and (c) DWT ${ }^{\text {st }}$ level values for the first case
In the second case, a three phase fault occurs in the upstream network at the $t=0.06 \mathrm{~s}$. the proposed method should detect the fault (that causes the islanding condition) before the utility circuit breaker operation. The utility current signal and the utility current zero sequence angle are shown in the Fig. 3a and Fig. 3b respectively. The DWT $1^{\text {st }}$ level is shown in Fig. 3c. This figure shows that the feature value for the second case is equal to 0.015 . The maximum Value for other levels is found in Table 2.
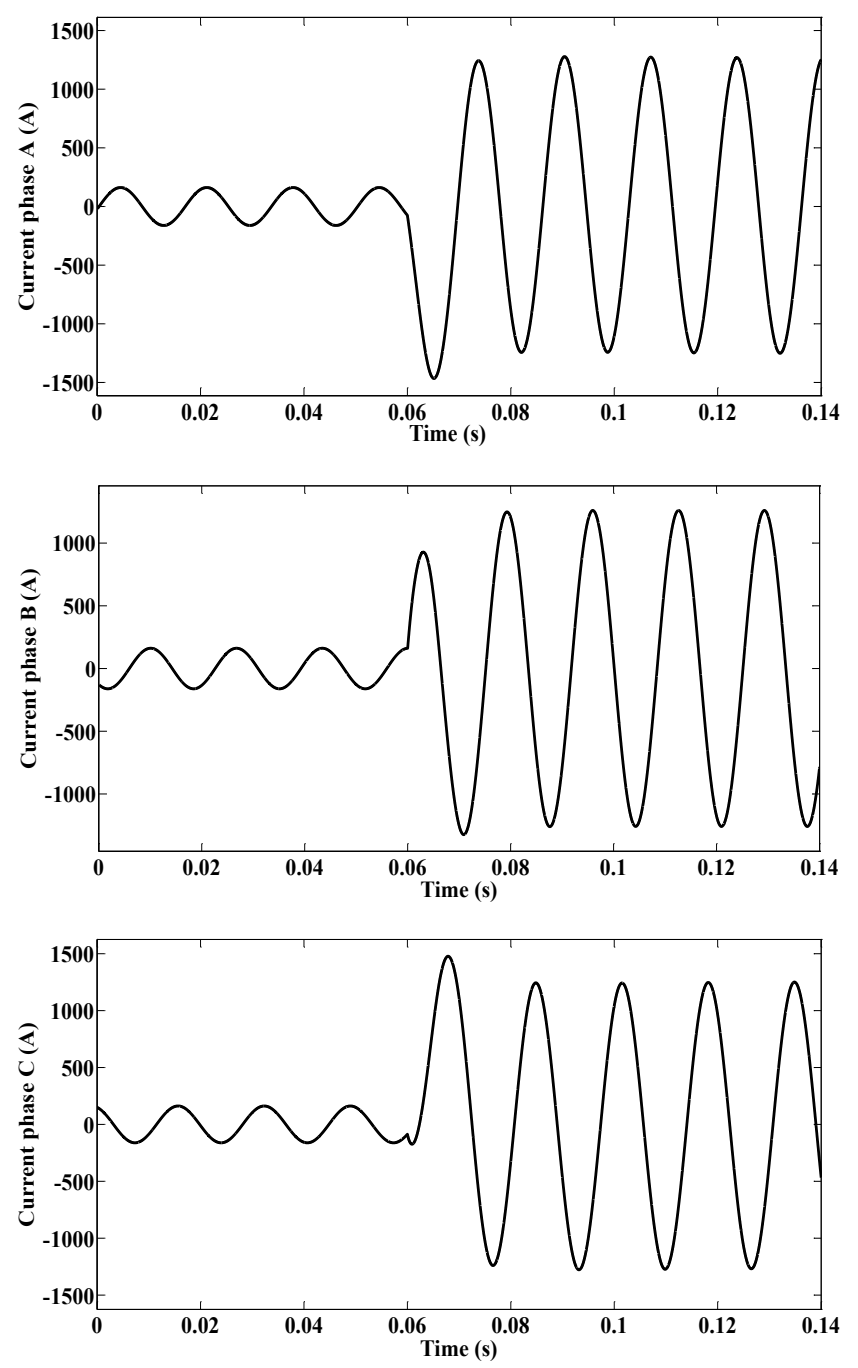

(a)

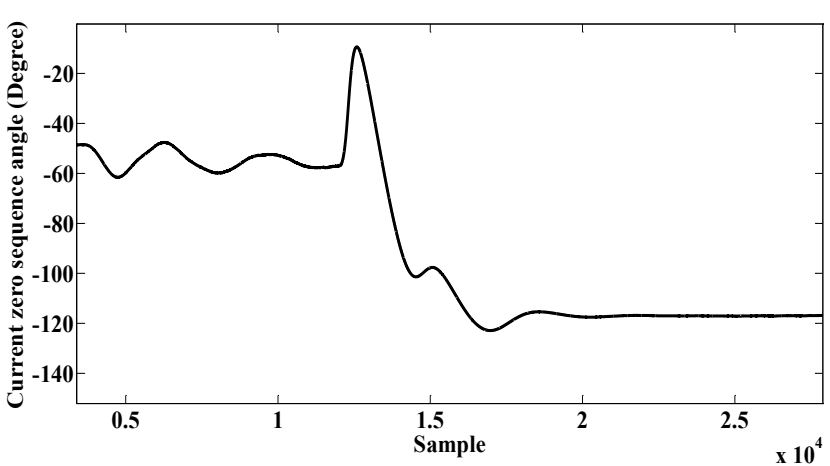

(b) 


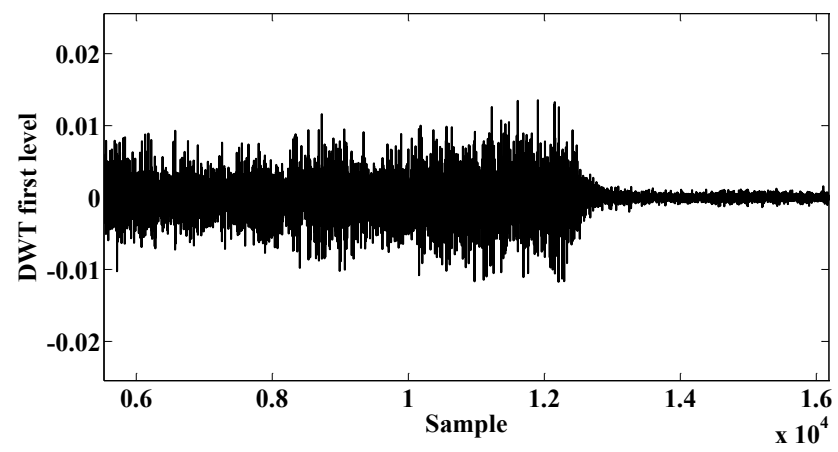

(c)

Figure 3. (a) Utility current signal, (b) zero sequence angle of utility current and (c) DWT 1st level values for the second case

In the third case, the network load reduction is occurred at the $\mathrm{t}=0.08 \mathrm{~s}$. This case is not an islanding condition and the feature that is extracted from the third case should be clearly different from the same value in the first and the second cases. Fig. $4 \mathrm{a}$ and Fig. $4 \mathrm{~b}$ show the utility current and the zero sequence angle of the utility current for the third case respectively. Fig.4c shows the DWT 1st level in this case. This figure shows that the feature value for the second case is equal to 66.7. The maximum Value for other levels is found in Table 2.
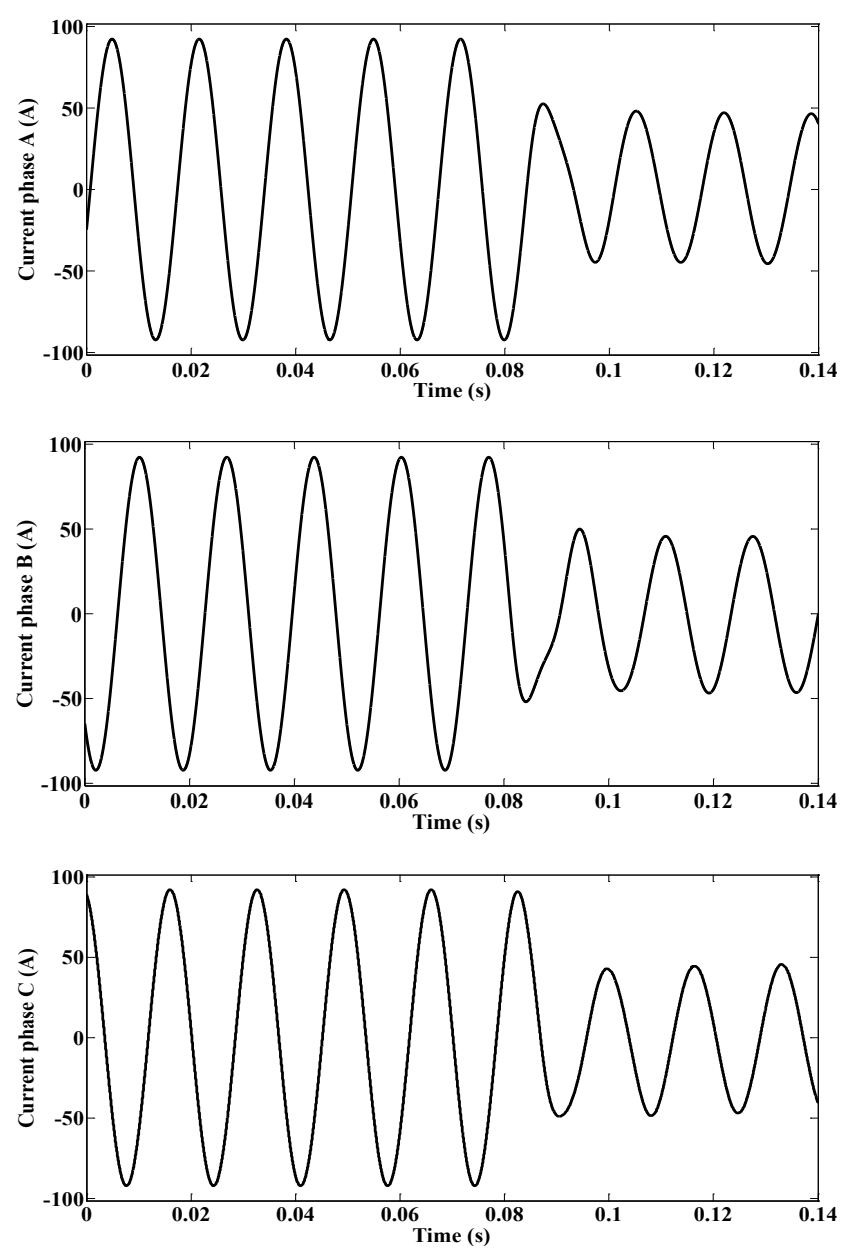

(a)

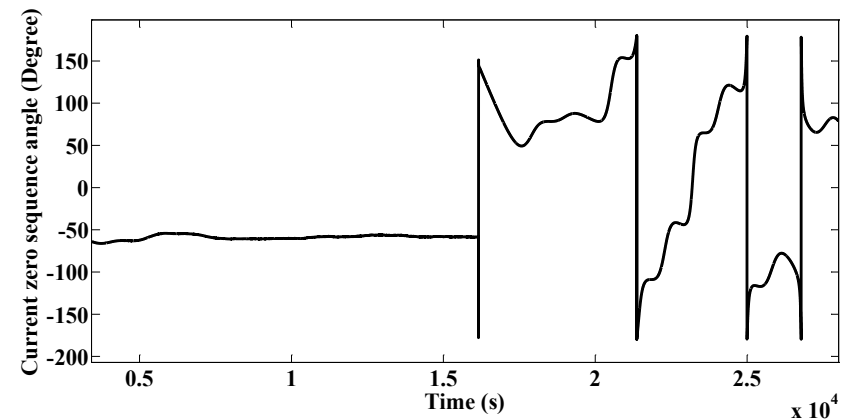

(b)

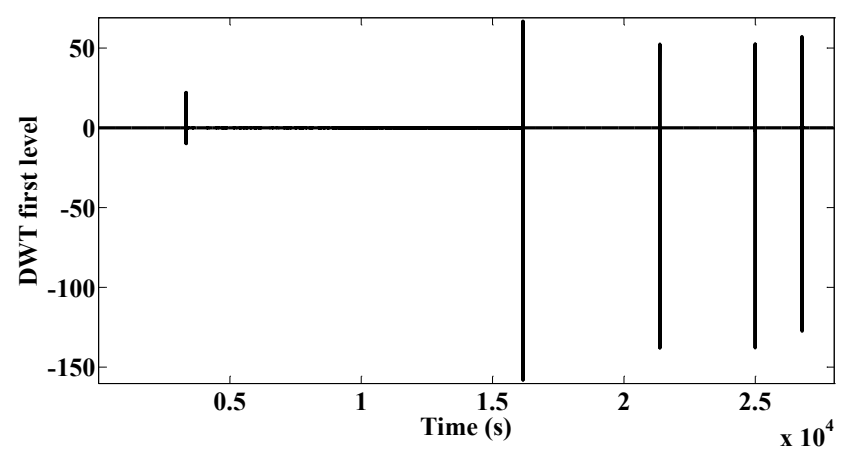

(c)

Figure 4. (a) Utility current signal, (b) zero sequence angle of utility current and (c) DWT $1^{\text {st }}$ level values for the third case

Table 2. The maximum values of DWT levels

\begin{tabular}{|c|c|c|c|}
\hline $\begin{array}{c}\text { DWT } \\
\text { Level } \\
\text { Number }\end{array}$ & $\begin{array}{c}\text { Maximum } \\
\text { Value in First } \\
\text { Case }\end{array}$ & $\begin{array}{c}\text { Maximum } \\
\text { Value in Second } \\
\text { Case }\end{array}$ & $\begin{array}{c}\text { Maximum } \\
\text { Value in Third } \\
\text { Case }\end{array}$ \\
\hline 1 & 0.95 & 0.015 & 66.7 \\
\hline 2 & 1.28 & 0.0265 & 58.6 \\
\hline 3 & 1.14 & 0.035 & 29 \\
\hline 4 & 3.65 & 0.055 & 56.8 \\
\hline 5 & 3.95 & 0.2 & 62 \\
\hline
\end{tabular}

The results of Table 2 show that the maximum value of the DWT levels in the first and second cases have a considerable difference with the same value in the third level. Therefore, the islanding conditions can be detected clearly from non-islanding conditions. For example, the maximum values of the DWT first level in the first and second cases are 0.95 and 0.015 , respectively while the same value in the third case is 66.7. This example shows that a certain threshold can be selected to distinguish between islanding conditions and non-islanding ones. It is obvious from Table 2 that the islanding condition can be detected from the maximum value of the DWT first level. As a result, the burden of calculation decreases. So, the less time is needed for islanding detection rather than selecting the higher level of the DWT.

\section{Conclusion}


The new method for islanding detection in distribution network is proposed in this paper. This method measures the current zero sequence angle at the utility side of utility circuit breaker. Due to movement of the measuring point from the PCC (in the local methods) to the utility side of the utility circuit breaker (in the proposed method), the islanding detection time is decreased. The measured signal is processed by discrete wavelet transform for extracting the feature. The maximum value of the DWT first level is selected as a feature for detecting the islanding conditions from non-islanding ones. Three cases are simulated to confirm the efficiency of the proposed method. The simulation results show that the features in the first and second cases have a considerable and clear difference by the same value in the third case.

\section{REFERENCES}

[1] CERT, "Integration of Distributed Energy Resources: The CERTS MicroGrid Concept”, LBNL-50829, 2003.

[2] M. J. Sanjari, G. B. Gharehpetian. Unified framework for secondary frequency and voltage control of autonomous microgrids, IET Generation, Transmission \& Distribution, Vol. 7, No. 9, 965-972.

[3] F. Katiraei, M. R. Iravani, P. W. Lehn. Micro-Grid autonomous operating during and subsequent to islanding process, IEEE Trans. Power Delivery, vol. 20, 248-257.
[4] H. H. Zeineldin, J. L. Kirtley. Islanding operation of inverter based distributed generation with static load models, Power and Energy Society General Meeting Conversion and Delivery of Electrical Energy in the 21 st Century, Pittsburgh, $1-6,2008$

[5] S. I. Jang, K. H. Kim. An islanding detection method for distributed generations using voltage unbalance and total harmonic distortion of current, IEEE Tran. Power Delivery, Vol. 19, No. 2, 745-752.

[6] M. A. Redfern, J. I. Barren, O. Usta. A new microprocessor based islanding protection algorithm for dispersed storage and generation units, IEEE Trans. Power Delivery, Vol. 10, No. 3, 1249-1254.

[7] J. Warin, W. H. Allen. Loss of mains protection, ERA Conference on Circuit Protection for industrial and Commercial Installation, London, UK, 1-12, 1990.

[8] M. E. Ropp, M. Begovic, A. Rohatgi. Analysis and performance assessment of the active frequency drift method of islanding prevention, IEEE Tran. Energy Conversion, Vol. 14, No. 3, 810-816.

[9] G. A. Smith, P. A. Onions, D. G. Infield. Predicting islanding operation of grid connected PV inverters, IEE Proc. Electric Power Applications, Vol. 147, 1-6, 2000.

[10] M. A. Refern, O. Usta, G. Fielding. Protection against loss of utility grid supply for a dispersed storage and generation unit, IEEE Trans. Power Delivery, Vol. 8, No. 3, 948-954.

[11] M. Ropp, K. Aaker, J. Haigh, N. Sabhah. Using power line carrier communications to prevent islanding, 28th IEEE Photovoltaic Specialist Conference, 1675-1678, 2000. 